\title{
BENARKAH UU MD3 MEMBUNGKAM ELEFTHERIA DI NEGARA (INDONESIA) MERDEKA? ${ }^{1}$
}

\author{
Achmad Zulfikar, S.IP., M.Si., M.H. \\ Pengamat Politik Hukum \\ Email: apa@kabarfikar.com
}

\begin{abstract}
RINGKASAN
Wacana publik terhadap revisi UU MD3 memunculkan pro dan kontra, termasuk di kalangan masyarakat (mahasiswa) FISIPOL UMY, sehingga kertas posisi ini ditujukan sebagai bahan diskusi untuk memperdalam pengetahuan mahasiswa terhadap polemik revisi UU MD3 dan menjadi langkah pengambilan sikap untuk permasalahan revisi UU MD3. Kertas posisi ini membahas tiga hal pokok diantaranya: dasar hukum UU MD3, latar belakang revisi UU MD3 dan problematika terhadap revisi UU MD3: benarkah sebagai upaya membungkam eleftheria di negara (Indonesia) merdeka?. Penyusunan kertas posisi ini menggunakan metode deskriptif kualitatif dengan teknik pengumpulan data menggunakan literature review, sumber data menggunakan publikasi yang dapat diakses secara dalam jaringan (daring/online), dan analisis data dengan reduksi data, penyajian data, dan penarikan kesimpulan/verifikasi. Kertas posisi ini menyoroti kekhawatiran yang muncul akibat dari revisi UU MD3 yang dianggap sebagai upaya membungkam eleftheria di negara merdeka, Indonesia yang turut dipengaruhi pengalaman masa lalu, dimana pemerintah pernah dianggap sebagai pelaku pembungkaman kebebasan berekspresi yang masih membekas di ingatan masyarakat. Sehingga, kekhawatiran yang muncul tidak hanya pada pada aturannya saja, melainkan juga pada implementasi yang terkadang tidak sesuai dengan ekspektasi sebagaimana tertulis.
\end{abstract}

Kata Kunci: Legislatif, UU MD3, Membungkam, Eleftheria, Kebebasan Berekspresi, Negara Merdeka

\begin{abstract}
The public discourse of the revision of the MD3 Law raises the pros and cons in Indonesian society, including the students of FISIPOL UMY. This position paper is intended as a discussion material to deepen the students' knowledge of the revision of the MD3 Law and consideration to take action from the revision of the MD3 Law. This position paper discusses three key issues: the legal basis of the MD3 Law, the revised background of the MD3 Law and the problematic of the revision of the MD3 Law: is it really an effort to silence eleftheria in an independent (Indonesia) country?. This position paper uses qualitative descriptive method with data collection techniques using literature review, then data sources using publicly accessible (online) publications, and data analysis with data reduction, data presentation, and conclusion/verification. This position paper highlights the concerns arising from the revision of the MD3 Law which is considered to be an attempt to block the freedom of expression (eleftheria) in an independent state, which has been influenced by past

1 Kertas Posisi yang dijadikan Bahan Diskusi dalam dalam kegiatan KOBAR (Mengkaji Obrolan Terbaru) dengan tema "Komprehensif UU MD3 (Majelis Permusyawaratan Rakyat, Dewan Perwakilan Rakyat, Dewan Perwakilan Daerah, dan Dewan Perwakilan Rakyat Daerah) sebagai Kebungkaman Eleftheria di Negara Merdeka" yang diselenggarakan oleh Dinas Kajian Strategis (KASTRAT) Badan Eksekutif Mahasiswa Fakultas Ilmu Sosial dan Ilmu Politik Universitas Muhammadiyah Yogyakarta pada 14 Maret 2018.
\end{abstract}


experience, where the Indonesian government was once regarded as the perpetrator of the silencing of freedom of expression which still remains in the public mind. Thus, the concerns that arise not only on the rules itself, but also the implementation that sometimes does not match expectations as written.

Keywords: Legislative, MD3 Law, Silencing, Eleftheria, Freedom of Expression, Independent Country

\section{PENDAHULUAN}

Publik Indonesia dalam beberapa minggu belakangan ini sedang aktif mengembangkan wacana dengan revisi kedua Undang-Undang Nomor 17 Tahun 2014 tentang MPR, DPR, DPD dan DPRD (UU MD3), utamanya kalangan warganet di dunia maya. Sejak UU MD3 disahkan pada Rapat Paripurna di DPR RI pada Senin (12/2/2018), warganet mulai membincangkan beberapa poin, utamanya stigma yang terbangun bahwa terdapat pasal yang bisa menyeret masyarakat yang mengkritik DPR akan dipidanakan.

Hal ini turut menjadi perhatian dari Dinas Kastrat BEM FISIPOL UMY melalui KOBAR yang mengangkat tema "Komprehensif UU MD3 sebagai Kebungkaman Elefheria di Negara Merdeka". Kajian ini berfokus pada bagaimana penyelesaian isu yang dikaji agar terealisasikan dan dapat mewakili suara masyarakat FISIPOL pada khususnya dan masyarakat UMY pada umumnya.[1] Tujuan dari diskusi ini diantaranya sebagai tempat pendalaman pengetahuan terhadap polemik revisi UU MD3 dan sebagai langkah pengambilan sikap untuk permasalahan revisi UU MD3.[2]

Lebih lanjut, BEM FISIPOL dalam kerangka acuan diskusi menyatakan bahwa UU (MD3) yang sudah 'disepakati' oleh DPR dan pihak eksekutif (pemerintah) di rasa cukup meresahkan masyarakat. Di satu sisi, UU tersebut dapat meningkatkan martabat dan kehormatan dari DPR. UU tersebut dinilai mampu untuk menguatkan posisi DPR agar dapat fokus dalam mengemban tugasnya sebagai wakil rakyat. Namun, di sisi lain, penolakan UU MD3 juga bersumber dari anggapan masyarakat bahwa UU tersebut dapat membungkam suara rakyat yang mengawasi dan mengkritisi setiap tindakan kebijakan dan pelaksanaan dari DPR.[4]

Menurut BEM FISIPOL terdapat tiga pasal kontroversial diantaranya: pertama, Pasal 73 ayat (3), (4) dan (5) terkait pemanggilan paksa melalui Kepolisian,; Kedua, Pasal 122 huruf $\mathrm{K}$ terkait langkah hukum terhadap orang perseorangan, kelompok, atau badan hukum yang merendahkan kehormatan DPR dan anggota DPR; dan ketiga, Pasal 245 ayat (1) terkait pemanggilan anggota DPR harus mendapatkan persetujuan tertulis dari Presiden setelah mendapat pertimbangan dari Mahkamah Kehormatan Dewan dan ayat (2) terkait pembatalan 
persetujuan tertulis dikarenakan anggota DPR tertangkap tangan melakukan tindak pidana; disangka melakukan tindak pidana kejahatan yang diancam pidana mati atau pidana seumur hidup; dan disangka melakukan tindak pidana khusus.[5]

Berdasarkan penjelasan di atas, maka dapat dipahami bahwa UU MD3 merupakan wacana publik yang memunculkan pro dan kontra, termasuk di kalangan masyarakat FISIPOL UMY, sehingga diskusi ini ditujukan untuk memperdalam pengetahuan terhadap polemik revisi UU MD3 dan menjadi langkah pengambilan sikap untuk permasalahan revisi UU MD3. Adapun pembahasan yang diamanahkan kepada pemantik diantaranya: (1) dasar hukum terkait UU MD3; (2) latar belakang dibuatnya revisi UU MD3 dan (3) problematika terhadap revisi UU MD3.[6] Sehingga, hasil dan pembahasan akan diarahkan untuk menjawab tiga pokok pembahasan tersebut.

\section{METODE}

Metode penyusunan kajian ini menggunakan deskriptif kualitatif. Teknik pengumpulan data menggunakan literature review. Sumber data menggunakan publikasi yang dapat diakses secara dalam jaringan (daring/online) utamanya pada media massa yang berafiliasi dengan objek yang diteliti yakni DPR sebagai lembaga pemrakarsa UU MD3 dan juga media yang mengutip pernyataan para narasumber yang berkaitan dengan MD3. Teknik analisis data menggunakan analisis kualitatif dan telaah kritis media. Proses analisis data yaitu reduksi data, penyajian data, dan penarikan kesimpulan/verifikasi dilakukan bersamaan dengan proses pengumpulan data.

\section{HASIL DAN PEMBAHASAN}

\section{Dasar Hukum UU MD3}

UU MD3 disahkan sebagai Undang-Undang Republik Indonesia Nomor 17 Tahun 2014 tentang Majelis Permusyawaratan Rakyat, Dewan Perwakilan Rakyat, Dewan Perwakilan Daerah dan Dewan Perwakilan Rakyat Daerah pada tanggal 5 Agustus 2014. UU ini terdiri atas 428 pasal dan 10 Bab. UU MD3 ini didasarkan pada empat pertimbangan utama antara lain: Pertama, bahwa untuk melaksanakan kedaulatan rakyat atas dasar kerakyatan yang dipimpin oleh hikmat kebijaksanaan dalam permusyawaratan/perwakilan, perlu mewujudkan lembaga permusyawaratan rakyat, lembaga perwakilan rakyat, dan lembaga perwakilan daerah yang mampu mengejawantahkan nilai-nilai demokrasi serta 
menyerap dan memperjuangkan aspirasi rakyat dan daerah sesuai dengan tuntutan perkembangan kehidupan berbangsa dan bernegara;

Kedua, bahwa untuk mewujudkan lembaga permusyawaratan rakyat, lembaga perwakilan rakyat, dan lembaga perwakilan daerah perlu menata Majelis Permusyawaratan Rakyat, Dewan Perwakilan Rakyat, Dewan Perwakilan Daerah, dan Dewan Perwakilan Rakyat Daerah; Ketiga bahwa Undang-Undang Nomor 27 Tahun 2009 tentang Majelis Permusyawaratan Rakyat, Dewan Perwakilan Rakyat, Dewan Perwakilan Daerah, dan Dewan Perwakilan Rakyat Daerah sudah tidak sesuai lagi dengan perkembangan hukum dan kebutuhan hukum masyarakat sehingga perlu diganti; Keempat bahwa berdasarkan pertimbangan sebagaimana perlu membentuk Undang-Undang tentang Majelis Permusyawaratan Rakyat, Dewan Perwakilan Rakyat, Dewan Perwakilan Daerah, dan Dewan Perwakilan Rakyat Daerah.[7]

Adapun UU yang dijadikan rujukan dalam UU MD3 ini diantaranya: Pasal 2, Pasal 3, Pasal 7A, Pasal 7B, Pasal 8, Pasal 9, Pasal 11, Pasal 13, Pasal 18 ayat (3), Pasal 19, Pasal 20, Pasal 20A, Pasal 21, Pasal 22 ayat (2), Pasal 22B, Pasal 22C, Pasal 22D, Pasal 23 ayat (2) dan ayat (3), Pasal 23E ayat (2) dan ayat (3), Pasal 23F ayat (1), Pasal 24A ayat (3), Pasal 24B ayat (3), Pasal 24C ayat (2) dan ayat (3), dan Pasal 37 ayat (1), ayat (2), ayat (3), dan ayat (4) Undang-Undang Dasar Negara Republik Indonesia Tahun 1945.[8]

Berdasarkan penjelasan di atas maka dapat diketahui bahwa UU MD3 disahkan pada tanggal 5 Agustus 2014 dengan 428 pasal dan 10 Bab dan empat pertimbangan yang termaktub di dalam Daftar Inventarisasi Masalah (DIM) sebagaimana tercantum dalam UU tersebut. UU yang dirujuk yakni 24 pasal dari UUD NRI Tahun 1945. Sehingga dapat dipahami bahwa UU MD3 ini merupakan implementasi dari pasal-pasal yang terdapat di dalam UU NRI Tahun 1945.

\section{Latar Belakang Revisi UU MD3}

UU MD3 dalam perjalanannya mengalami tiga kali perubahan menurut jejak digital di Kompas.com. Pertama, revisi UU MD3 jilid I, KMP vs KIH. Revisi Undang-undang MD3 kala itu disahkan pada 8 Juli 2014, sehari menjelang Pemilu Presiden 2014. Prosesnya berlangsung setelah Pemilu Legislatif 2014 selesai. Saat itu, polarisasi Koalisi Indonesia Hebat (KIH) selaku kumpulan partai koalisi pemerintah dan Koalisi Merah Putih (KMP) masih kuat. Dengan adanya revisi UU MD3 pada Juli 2014 maka tak satu pun perwakilan KIH yang duduk di kursi pimpinan DPR. Selain mengubah sistem penetapan pimpinan DPR, 
revisi UU MD3 juga mengubah Pasal 245, di mana pemeriksaan anggota DPR yang terlibat tindak pidana tak butuh izin presiden, melainkan Mahkamah Kehormatan Dewan (MKD). Dengan demikian pasal yang direvisi ialah Pasal 84 tentang penetapan pimpinan DPR dan Pasal 245 tentang pemeriksaan anggota DPR yang terlibat tindak pidana.

Kedua, revisi UU MD3 jilid II, akomodasi KIH ke pimpinan AKD. Revisi UU MD3 kali ini bernuansa pengakomodasian KIH ke dalam unsur pimpinan Alat Kelengkapan Dewan (AKD) berupa sejumlah komisi dan badan. Bila dulunya pimpinan komisi dan badan di DPR hanya diisi oleh perwakilan KMP, dengan adanya revisi UU MD3 pada Desember 2014 maka perwakilan KIH mulai mengisi jabatan tersebut. Revisi tersebut ialah menambah satu kursi pimpinan AKD, sehingga perwakilan KIH bisa masuk ke dalamnya. Revisi itu dinilai sebagai akhir konflik dari KIH dan KMP di parlemen. Selain itu revisi UU MD3 juga mewajibkan semua pihak menjalankan rekomendasi yang diberikan DPR berupa hasil rapat dengar pendapat, rapat kerja, rapat panitia khusus, dan rapat panitia kerja. Ada delapan pasal UU MD3 yang dilakukan perubahan oleh DPR, yakni Pasal 74 Ayat 3,4, 5 dan 6; Pasal 97 Ayat 2; 98 Ayat 7,8 dan 9; Pasal 104 Ayat 2; Pasal 109 Ayat 2; Pasal 121 Ayat 2; dan Pasal 152 Ayat 2.

Ketiga, Revisi UU MD3 jilid III, akomodasi PDI-P dalam pimpinan DPR dan MPR. Revisi UU MD3 kali ini bernuansa pengakomodasian partai pemenang pemilu legislatif, yang tak kunjung mendapat kursi pimpinan DPR dan MPR. Pemerintah dan delapan fraksi menyepakati pembahasan revisi UU MD3 soal penambahan kursi pimpinan MPR dan DPR dibawa ke rapat paripurna untuk segera disetujui. Hal itu mengubah Pasal 84 tentang komposisi pimpinan DPR. Ada pula revisi pada Pasal 245 tentang pemeriksaan anggota DPR yang terlibat tindak pidana. Pada 2015, ketentuan pemeriksaan atas seizin MKD dibatalkan Mahkamah Konstitusi sehingga kembali atas seizin presiden. Namun, DPR dalam revisi kali ini menambahkan ketentuan pertimbangan MKD sebelum presiden memberi izin. Tetapi ketentuan tersebut tidak berlaku bagi anggota DPR yang tertangkap tangan saat melakukan tindak pidana, terlibat tindak pidana khusus, dan pidana dengan ancaman hukuman mati atau seumur hidup. Selain itu, Pasal 73 tentang pemanggilan paksa pihak yang diperiksa DPR pun turut direvisi. Dalam klausul pasal 73 revisi Undang-undang No. 17 Tahun 2014 tentang MPR, DPR, DPRD, dan DPD (MD3) itu, ditambahkan frase "wajib" bagi polisi membantu memanggil paksa pihak yang diperiksa DPR namun enggan datang.[9]

Berdasarkan penjelasan di atas maka dapat dipahami bahwa UU MD3 mengalami tiga kali perubahan terhitung sejak revisi terbatas dari UU No. 27 Tahun 2009 ke UU No. 17 Tahun 2014 yang dimulai sejak Juli 2014 dan selesai pada Agustus 2014, kemudian 
dilakukan lagi perubahan pada UU No. 17 Tahun 2014 pada Desember 2014, dan perubahan kedua terhadap UU No. 17 Tahun 2014 pada Februari 2018. Hal ini merupakan rekam jejak digital yang penting sebagai pengingat atas setiap momentum yang terjadi dalam revisi UU MD3.

\section{Problematika terhadap Revisi UU MD3: Benarkah Sebagai Upaya Membungkam Eleftheria di Negara (Indonesia) Merdeka?}

Sebelum mengkaji lebih jauh problematika terhadap revisi UU MD3. Menarik untuk memahami penggunaan diksi "Eleftheria". Kata ini cukup asing dalam wacana publik di Indonesia, jika ditelusuri melalui mesin pencari, maka akan ditemukan penjelasan bahwa Eleftheria memiliki arti "freedom" atau kebebasan dari bahasa Yunani[10]. Sehingga, kajian ini secara umum dapat dipahami apakah revisi UU MD3 membungkam kebebasan (berekspresi) di negara merdeka? Hal ini akan dibahas pada bagian ini.

Jika berbicara dalam konteks kebebasan berekspresi di sebuah negara Demokrasi dan Merdeka, maka yang terbayang adalah kebebasan yang bertanggungjawab. Namun demikian maraknya informasi hoax dan framing berita untuk suatu kepentingan tertentu menjadikan situasi wacana dan opini publik di Indonesia tidak kondusif. Sehingga terciptalah mekanisme pertahanan diri dari masing-masing lembaga untuk melindungi diri dari 'serangan' hoax yang dirasakan semakin meresahkan. Fenomena ini tidak dapat dilepaskan dari perkembangan Teknologi, Informasi dan Komunikasi (TIK) yang semakin canggih dari waktu ke waktu.

Kecepatan akses informasi jaman now, tidak diikuti dengan kemampuan pengguna (masyarakat) untuk menyaring informasi dan melakukan kroscek terhadap kebenaran informasi yang diterima. Kecenderungan yang terjadi yakni masyarakat menerima begitu saja informasi dari berbagai media, utamanya media sosial. Tidak hanya itu, lebih parahnya lagi kecenderungan yang semakin mengemuka adalah terjadinya polarisasi yang cukup mencolok di masyarakat dalam memandang suatu wacana publik. Walau tidak dapat dimungkiri bahwa pro dan kontra tentu selalu ada dalam setiap wacana, namun yang terjadi adalah masyarakat saling menuding dan cenderung 'memaksakan' kebenaran dari versinya masing-masing.

Problematika terhadap revisi UU MD3 juga tidak terlepas dari dinamika yang terjadi di masyarakat. Berdasarkan kajian terhadap latar belakang revisi UU MD3, maka telah terlihat polarisasi telah terjadi di internal DPR sendiri yakni adanya kubu KIH dan KMP. Kemudian berangsur meluas ke masyarakat yang ikut mengasosiasikan dirinya sebagai 'pendukung' dan 'oposisi' pemerintah mengikuti sikap dari wakil rakyatnya di Senayan. 
Polarisasi semakin nyata ketika perubahan kedua UU MD3 disahkan pada 12 Februari 2018 lalu. Publik kembali terbelah menjadi dua kutub yakni 'pro' dan 'kontra' terhadap perubahan kedua UU MD3.

Pemantik dalam hal ini hanya membantu BEM FISIPOL untuk memantik peserta diskusi untuk berdiskusi lebih jauh mengenai komprehensif UU MD3. Jika dilihat dari tema yang dipilih oleh panitia, maka kekhawatiran yang dapat pemantik tangkap adalah revisi UU MD3 berpotensi untuk membungkam kebebasan berekspresi yang disimbolkan dengan kata 'eleftheria'. Oleh karena itu pembahasan ini akan membahas seputar kekhawatiran yang muncul tersebut.

Pada dasarnya kebebasan berekspresi telah dijamin dalam UUD NRI 1945 Pasal 28F yang dijelaskan bahwa: "Setiap orang berhak untuk berkomunikasi dan memperoleh informasi untuk mengembangkan pribadi dan lingkungan sosialnya, serta berhak untuk mencari, memperoleh, memiliki, menyimpan, mengolah, dan menyampaikan informasi dengan menggunakan segala jenis saluran yang tersedia." Selain itu, Pasal 5 UU No. 9 Tahun 1998 tentang Kemerdekaan Menyampaikan Pendapat di Muka Umum memberikan hak yang sama kepada warga Indonesia untuk mengeluarkan pikiran secara bebas sekaligus memperoleh perlindungan hukum.

Satu tahun setelahnya muncul aturan tersebut, pemerintah mengesahkan UU No. 39 Tahun 1999 tentang Hak Asasi Manusia yang melindungi hak tiap orang untuk berkomunikasi dan memperoleh informasi menggunakan media apapun. Lebih jauh lagi, dalam hukum internasional, Pasal 19 Deklarasi Universal tentang Hak Asasi Manusia juga jelas melindungi kebebasan berpendapat. Pasal tersebut berbunyi, "Setiap orang berhak atas kebebasan mempunyai dan mengeluarkan pendapat; dalam hal ini termasuk kebebasan menganut pendapat tanpa mendapat gangguan, dan untuk mencari, menerima dan menyampaikan keterangan-keterangan dan pendapat dengan cara apa pun dan dengan tidak memandang batas-batas".

Jika merujuk pada aturan yang telah ada di Indonesia, maka kebebasan berekspresi telah diatur secara berlapis mulai dari UUD NRI 1945 Pasal 28F, Pasal 5 UU No. 9 Tahun 1998 tentang Kemerdekaan Menyampaikan Pendapat di Muka Umum, UU No. 39 Tahun 1999 tentang Hak Asasi Manusia. Bahkan Pasal 19 Deklarasi Universal tentang Hak Asasi Manusia telah menjaminnya. Namun selanjutnya kekhawatiran yang muncul tentu bukan pada aturannya melainkan pada implementasi yang terkadang tidak sesuai dengan ekspektasi sebagaimana tertulis. Ditambah lagi dengan pengalaman masa lalu, dimana pemerintah pernah dianggap sebagai pelaku pembungkaman kebebasan berekspresi yang masih 
membekas di ingatan masyarakat. Hal-hal di atas merupakan kekhawatiran yang muncul akibat dari revisi UU MD3 yang dianggap sebagai upaya membungkam eleftheria di negara merdeka, Indonesia.

\section{CATATAN PENUTUP}

Mengakhiri kertas posisi ini, pemantik berharap diskusi KOBAR 2 dapat menghasilkan rekomendasi yang solutif sebagaimana tujuan diskusi ini diadakan sehingga dapat membawa aspirasi masyarakat FISIPOL UMY agar dapat didengar oleh para pengambil kebijakan dan masyarakat luas, serta berkontribusi terhadap penyelesaian permasalahan bangsa.

\section{REFERENSI}

[1] Term of Reference Mengkaji Obrolan Terbaru Dinas Kajian Strategis BEM FISIPOL UMY. h. 1.

[2] Ibid. h. 3.

[3] Lampiran Term of Reference Mengkaji Obrolan Terbaru Dinas Kajian Strategis BEM FISIPOL UMY. h. 1.

[4] Ibid. hh. 1-2.

[5] Term of Reference. op. cit. h. 3.

[6] Ibid.

[7] DPR RI. Undang-Undang Republik Indonesia Nomor 17 Tahun 2014 tentang Majelis Permusyawaratan Rakyat, Dewan Perwakilan Rakyat, Dewan Perwakilan Daerah dan Dewan Perwakilan Rakyat Daerah. Diakses melalui www.dpr.go.id/dokjdih/document/uu/UU_2014_17.pdf, pada 13 Maret 2018.

[8] Ibid.

[9] Kompas.com. (2018). Perjalanan Revisi UU MD3 yang Penuh Nuansa Pragmatisme Politik. Diakses melalui https://nasional.kompas.com/read/2018/02/09/08515531/perjalanan-revisi-uu-md3-yangpenuh-nuansa-pragmatisme-politik?page=all pada 13 Maret 2018.

[10] Greek Names. Eleftheria. Diakses melalui https://www.greek-names.info/eleftheria/ pada 13 Maret 2018. 


\section{BAHAN BACAAN}

DonnyBU. (2012). Internet, Kebebasan Berekspresi dan Hak Asasi Manusia. Diakses melalui https://donnybu.com/2012/07/25/internet-kebebasan-berekspresi-dan-hak-asasi-manusiaham/ pada 13 Maret 2018.

Harian Analisa. (2016). UU ITE dalam Kebebasan Berekspresi. Diakses melalui http://harian.analisadaily.com/opini/news/uu-ite-dalam-kebebasanberekspresi/210234/2016/02/01 pada 13 Maret 2018.

Heru Riwan. (2013). UUD 45 Pasal 28 Vs UU ITE. Diakses melalui https://www.kompasiana.com/heruriswan/uud-45-pasal-28-vs-uuite_552fbdfc6ea8340d2d8b4578 pada 13 Maret 2018.

Sindonews.com (2014). Ini Pasal-Pasal Revisi dalam UU MD3 Baru. Diakses melalui https://nasional.sindonews.com/read/933728/12/ini-pasal-pasal-revisi-dalam-uu-md3-baru1417795011 pada 13 Maret 2018.

Detik.com. https://news.detik.com/berita/d-3864339/formappi-nilai-pengesahan-revisi-uumd3-tanda-buruknya-kinerja-dpr

MediaIndonesia.com. http://www.mediaindonesia.com/news/read/146021/presiden-tidakakan-tanda-tangani-uu-md3-hasil-revisi-kedua/2018-02-20

BBC ID. (2018). UU MD3 merupakan 'kriminalisasi' terhadap rakyat yang kritis pada DPR. Diakses melalui http://www.bbc.com/indonesia/indonesia-43029117 pada 13 Maret 2018.

http://www.dpr.go.id/berita/detail/id/19863/t/BK+DPR+Minta+Masyarakat+Tabayyun+Terh adap+Pasal+Kontroversial+UU+MD3

https://nasional.kompas.com/read/2014/11/26/14000041/Ihwal.Revisi.UU.MD3

https://nasional.kompas.com/read/2018/02/12/05375491/di-draf-revisi-uu-md3-mkd-bakallapor-polisi-bila-martabat-dpr-direndahkan

https://news.idntimes.com/indonesia/teatrika/uu-md3-jadi-bumerang-ini-jawaban-paraanggota-dewan-1

http://www.dpr.go.id/berita/detail/id/19498/t/Baleg+Sampaikan+14+Poin+Revisi+UU+MD3 http://www.dpr.go.id/berita/detail/id/19419/t/Revisi+UU+MD3+untuk+Perkuat+Fungsi+Legi slasi

http://www.dpr.go.id/berita/detail/id/19573/t/Revisi+UU+MD3+Tidak+Mengandung+Delik+ Pidana

http://www.dpr.go.id/berita/detail/id/19491/t/Revisi+UU+MD3+untuk+Minimalisir+Krimina lisasi+Tupoksi+DPR

http://www.dpr.go.id/berita/detail/id/19439/t/Revisi+UU+MD3+Atur+Pemanggilan+Paksa+d engan+Bantuan+Polri 